\title{
Low-dose statin treatment increases prostate cancer aggressiveness
}

\author{
Alfredo Caro-Maldonado ${ }^{1}$, Laura Camacho ${ }^{1,2, *}$, Amaia Zabala-Letona ${ }^{1,3, *}$, Verónica \\ Torrano $^{1,3}$, Sonia Fernández-Ruiz ${ }^{1,3}$, Kepa Zamacola-Bascaran ${ }^{1}$, Leire Arreal ${ }^{1}$, \\ Lorea Valcárcel-Jiménez ${ }^{1}$, Natalia Martín-Martín ${ }^{1,3}$, Juana M. Flores ${ }^{4}$, Ana R. \\ Cortazar $^{1}$, Patricia Zúñiga-García ${ }^{1}$, Amaia Arruabarrena-Aristorena ${ }^{1}$, Fabienne \\ Guillaumond ${ }^{5,6,7,8}$, Diana Cabrera ${ }^{1}$, Juan M. Falcón-Perez ${ }^{1,9,10}$, Ana M. Aransay ${ }^{1,9}$, \\ Antonio Gomez-Muñoz ${ }^{2}$, Mireia Olivan ${ }^{11}$, Juan Morote ${ }^{11}$ and Arkaitz Carracedo ${ }^{1,2,3,10}$ \\ ${ }^{1}$ CIC bioGUNE, Bizkaia Technology Park, Derio, Spain \\ 2 Biochemistry and Molecular Biology Department, University of the Basque Country, Bilbao, Spain \\ ${ }^{3}$ CIBERONC, Madrid, Spain \\ ${ }^{4}$ Department of Animal Medicine and Surgery, School of Veterinary Medicine, Complutense University of Madrid, Madrid, \\ Spain \\ ${ }^{5}$ Centre de Recherche en Cancérologie de Marseille, U1068, Institut National de la Santé et de la Recherche Médicale, Paris, \\ France \\ ${ }^{6}$ Institut Paoli-Calmettes, Marseille, France \\ ${ }^{7}$ UMR 7258, Centre National de la Recherche Scientifique, Paris, France \\ ${ }^{8}$ Université Aix-Marseille, Marseille, France \\ ${ }^{9}$ Centro de Investigación Biomédica en Red de Enfermedades Hepáticas y Digestivas, Madrid, Spain \\ ${ }^{10}$ IKERBASQUE, Basque foundation for science, Bilbao, Spain \\ ${ }^{11}$ Department of Urology and Research Group in Urology, Vall d'Hebron Hospital, Vall d'Hebron Research Institute, and \\ Universitat Autònoma de Barcelona, Barcelona, Spain \\ * These authors have contributed equally to this work \\ Correspondence to: Arkaitz Carracedo, email: acarracedo@cicbiogune.es
}

Keywords: prostate cancer; statins; cholesterol; obesity; mouse models

Received: July 13, $2017 \quad$ Accepted: October 13, $2017 \quad$ Published: October 31, 2017

Copyright: Caro-Maldonado et al. This is an open-access article distributed under the terms of the Creative Commons Attribution License 3.0 (CC BY 3.0), which permits unrestricted use, distribution, and reproduction in any medium, provided the original author and source are credited.

\section{ABSTRACT}

Prostate cancer is diagnosed late in life, when co-morbidities are frequent. Among them, hypertension, hypercholesterolemia, diabetes or metabolic syndrome exhibit an elevated incidence. In turn, prostate cancer patients frequently undergo chronic pharmacological treatments that could alter disease initiation, progression and therapy response. Here we show that treatment with anti-cholesterolemic drugs, statins, at doses achieved in patients, enhance the pro-tumorigenic activity of obesogenic diets. In addition, the use of a mouse model of prostate cancer and human prostate cancer xenografts revealed that in vivo simvastatin administration alone increases prostate cancer aggressiveness. In vitro cell line systems supported the notion that this phenomenon occurs, at least in part, through the direct action on cancer cells of low doses of statins, in range of what is observed in human plasma. In sum, our results reveal a prostate cancer experimental system where statins exhibit an undesirable effect, and warrant further research to address the relevance and implications of this observation in human prostate cancer. 


\section{INTRODUCTION}

The initiation, progression and therapeutic eradication of cancer is largely associated to the evolving mutational landscape of the tumor [1]. However, tissuespecific factors, the tumor microenvironment and the immune activation status are determinant factors of cancer cell survival and progression [2]. Critically, systemic metabolic alterations, nutrition, obesity and comorbidity-derived long-term therapies in elderly population shape the incidence and aggressiveness of cancer in our society [3-6]. Prostate cancer (PCa) is among the most frequent tumor type in men, and the main risk factors include family history, race and age [7]. Importantly, due to its predominant diagnosis in men above 60 years old, comorbidities are frequent. These include obesity, metabolic syndrome, arterial hypertension and diabetes [8]. In turn, $\mathrm{PCa}$ patients at the time of diagnosis are commonly subject to chronic therapies. Anti-hypercholesterolemic treatment is prescribed to millions of individuals around the globe in the form of statins, and their benefits and harms have been studied [9]. Due to their extensive and chronic use, it is of the utmost importance to carefully evaluate the impact of this long-term therapy on the biology of cancer, at doses and administration modes achieved in human subjects. In this study, we evaluated the impact of statin treatment in the pathogenesis and progression of $\mathrm{PCa}$. Through the use of PCa mouse models, cellular systems and observational studies in patients we demonstrate that treatment with these compounds is associated to increased aggressive features in this disease.

\section{RESULTS}

Anti-hypercholesterolemic treatments are often prescribed in the context of overweight or obesity [16]. Therefore, in order to evaluate the impact of statins (the main family of anticholesterolemic compounds, inhibitors of the mevalonate pathway enzyme Hydroxymethyl glutaryl CoA reductase - HMGCR) in PCa biology, we first evaluated the effect of statin exposure in the context of obesity in Pten prostate-specific heterozygous mice $\left(\right.$ Pten $\left.^{p c+/}\right)$, which exhibit a weak, non-cancerous phenotype $[10,17]$. We focused on the predominant statin used in the clinic, simvastatin. It is worth noting that the hydrophilic nature differs among statins, which could lead to distinct biological consequences in vivo [18]. We queried the available bibliography (Supplementary Table 1) and determined a low dose of simvastatin with proven biological activity [19]. Simvastatin was loaded in food pellets and provided ad libitum, thus enabling the uptake of simvastatin in an administration mode and concentration comparable to human subjects, including the activation of the drug in the liver [20]. We established an experimental design in which we induced obesity by feeding the mice with western diet (containing high fat and carbohydrates) [21], and once the obesity was achieved, simvastatin was loaded to the obesogenic diet (Figure 1a for experimental design). At the end of the experiment, the weight of the mice on western diet was significantly increased compared to mice on standard diet $(45.44 \pm 1.34$ gr versus 40.72 \pm 2.15 gr, $p=0.04$ ), whereas simvastatin addition to western diet did not have an impact on this parameter ( $46.83 \pm 1.05 \mathrm{gr}, p=0.43)$. The combination of obesity and statin treatment increased prostate mass (Figure 1b). At the histological level, obese Pten $^{p c+/}$ mice exhibited $50 \%$ incidence of prostate intraepithelial neoplasia (PIN) at 11 months of age, without the appearance of invasive carcinoma lesions (Figure 1c, d). Strikingly, simvastatin treatment administered after the onset of obesity (Figure 1a) led to invasive cancerous lesions with an incidence of $45 \%$, a phenotype only achieved in this mouse model when both copies of Pten are lost in the prostate epithelium $[10,13]$ (Figure 1c, 1d). Molecular analysis of these prostates revealed that simvastatin treatment exacerbated cell proliferation, accounted by Ki67 positivity (Figure $1 \mathrm{~d}, 1 \mathrm{e})$. These results provide unprecedented evidence for an undesired consequence of the treatment with statins in obese individuals with genetic predisposition to develop PCa.

We next evaluated the impact of statin treatment on PCa initiation using a Pten prostate-specific knockout $\left(\right.$ Pten $\left.^{p c-/}\right)$, which allows the study of proliferative burst under oncogenic signalling [13, 17]. Four-week statin treatment in Pten ${ }^{p-1 /}$ at the time of Pten excision and disease onset ( 8 weeks of age) resulted in an increased prostate mass and proliferation, without overt histological changes (Figure 2).

$\mathrm{PCa}$ initiation, progression and resistance to therapy depend on distinct molecular mechanisms. Advanced PCa is currently treated with androgen-deprivation therapy [22]. Previous reports have documented that Pten ${ }^{p c-1-}$ mice subject to orchiectomy exhibit overall pathological response [23]. Therefore, we performed surgical castration in order to address effects of statins on cancer cell biology beyond proliferation (Supplementary Figure 1a). In line with the undesirable effect of statin treatment observed in the other experimental systems, we observed a trend towards increased prostate mass and castration resistance in simvastatin-treated mice (Supplementary Figure 1b-d), in the absence of a significant alteration in cell proliferation (Supplementary Figure 1d, e).

In sum, the use of a faithful mouse model of $\mathrm{PCa}$ uncovers an unexpected effect of simvastatin that is associated to the increase of $\mathrm{PCa}$ cell proliferation, cancer initiation and resistance to therapy.

Our data provides evidence of the undesirable effect of simvastatin in murine PCa. To extrapolate these results to human $\mathrm{PCa}$, we took advantage of a human $\mathrm{PCa}$ cell line, $\mathrm{PC} 3$, and evaluated the impact of simvastatin feeding on tumor growth in subcutaneous xenografts. In line 
with our previous results, simvastatin fed mice exhibited significantly heightened tumor growth rate (Figure $3 a$ ).

Multiple reports have documented the antitumoral effect of statins in vitro. The majority of these studies rely on doses of these compounds in the micromolar range [24-45] (Supplementary Table 2). However, the concentration of statins found in plasma of patients subject to anti-cholesterolemic treatments is in the $\mathrm{nM}$ range [46]. Therefore, we sought to establish an in vitro experimental model that would recapitulate the concentration of statins achieved in patients. To this end, we first corroborated the reported effects of high simvastatin doses. Micromolar doses of simvastatin elicited an anti-proliferative and cytotoxic response in $\mathrm{PCa}$ cells (Supplementary Table 2; Supplementary Figure 2a, b). Next, we designed an experimental approach aimed at ascertaining the cell autonomous biological consequences of low simvastatin doses in PCa cells. We pre-treated PC3 cells with $50 \mathrm{nM}$ simvastatin for a minimum of 7 days, which did not result in any sign of toxicity in twodimensional growth assays (Figure 3b, Supplementary Figure 2c). This treatment schedule did not affect cell migration (Supplementary Figure 2d), but surprisingly resulted in elevated self-renewal capacity and anchorageindependent growth (Figure 3c, 3d). Of note, the effect of simvastatin in vitro was recapitulated in other cell lines (LNCaP and 22RV1, Figure 3d) and with an alternative HMGCR inhibitor (fluvastatin, Supplementary Figure 2e). Moreover, moderate genetic inhibition of HMGCR with two independent doxycycline-inducible shRNAs a

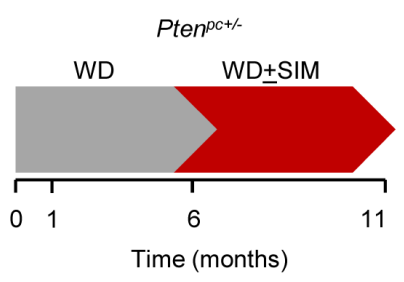

d

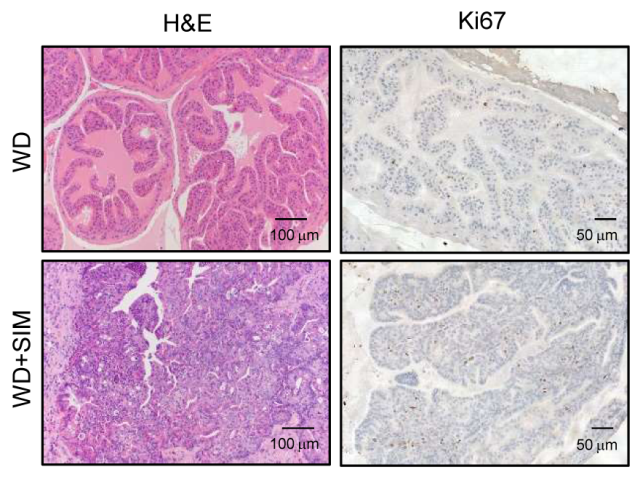

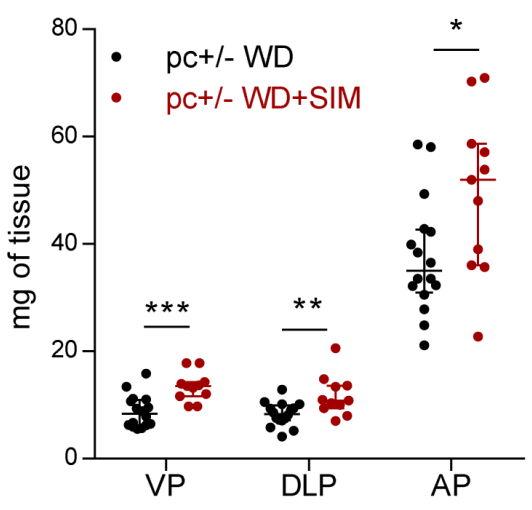

C

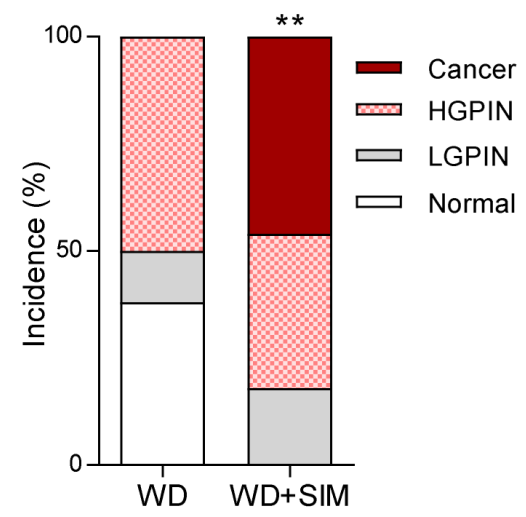

e

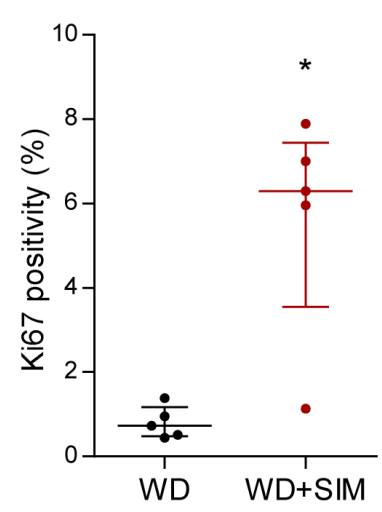

Figure 1: Simvastatin administration cooperates with obesogenic diets to drive prostate cancer. a. Schematic representation of the experimental design. 4-6 week-old prostate-specific Pten-heterozygous (Pten $\left.{ }^{p+t /} ; p c+/-\right)$ mice were fed with western diet (WD) to induce obesity. At 6 months of age, mice were randomly assigned to WD or WD loaded with simvastatin (WD + SIM) and fed for 5 months, and tissues were harvested and analysed. b. Prostate lobes weights of Pten-heterozygous (Pten ${ }^{p+/-} ; p^{c+/-)}$ mice fed with WD $(n=16)$ or WD + SIM $(n=11)$. VP, DLP, AP refer to ventral, dorsolateral and anterior prostates, respectively. c. Histopathological characterization of the prostate (Normal: no lesions; LGPIN: Low-grade prostatic intraepithelial neoplasia; HGPIN: High-grade prostatic intraepithelial neoplasia; Cancer: prostate adenocarcinoma) (WD, $n=16$, WD+SIM, $n=11$ ). d. Representative histological images of the prostate. Left, H\&E (Haematoxylin-eosin) and right, Ki67 staining. WD shows non-cancerous tissue, WD+SIM shows adenocarcinoma. e. Quantification of Ki67 positive nuclei (\%), indicating proliferating cells (WD, $n=5$; WD SIM, $n=5$ ). Statistical analysis: Mann-Whitney statistic test (b, e) and Chi Square test with 3 degree freedom (c). Error bars represent median with interquartile range. ${ }^{*} p<0.05,{ }^{* *} p<0.01,{ }^{* * *} p<0.001$. 
(Supplementary Figure 2f, g) elicited an effect comparable to simvastatin in anchorage-independent growth. Conversely, subtle HMGCR over-expression elicited the predicted opposing effect (Supplementary Figure $2 \mathrm{f}, \mathrm{h}$ ).

Since anchorage-independent growth and selfrenewal capacity are required steps in tumor re-initiation and metastatic seeding [47], we evaluated whether PC3 cells treated for 7 days with $50 \mathrm{nM}$ simvastatin would harbour elevated metastatic capacity. To this end, we injected PC3 cells pre-treated with vehicle or simvastatin in the tail vein of immunocompromised mice, and analysed the appearance of lung metastatic lesions (Supplementary Figure $2 \mathrm{i}$ right). Simvastatin treatment did not reduce metastatic burden, but rather resulted in increased rate of lung metastasis, which did not reach statistical significance ( $p=0.1$ ) probably owing to the low number of mice (Supplementary Figure 2i). In sum, our results support the existence of a biological context where statin treatment could promote features of PCa aggressiveness.

The effect of statins could be associated to the alteration in major oncogenic signalling pathways sustaining PCa function. Therefore, we evaluated the levels and/or activity of androgen receptor (AR), Phosphoinositide 3-kinase (PI3K, using as a readout serine 473 phosphorylation of AKT) and mitogen activated protein kinase (MAPK, using as a readout tyrosine 202/204 phosphorylation of ERK - extracellular signal regulated kinase) in AR-expressing LNCaP (AR- a

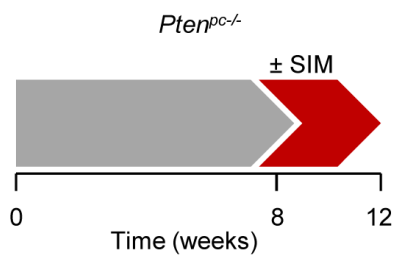

d

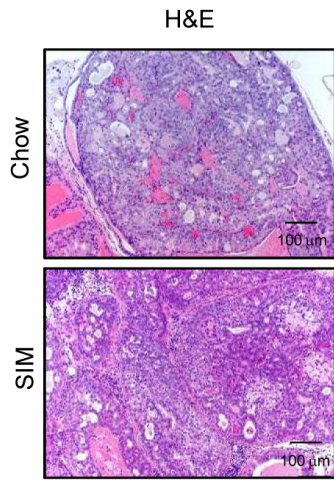

\section{b}

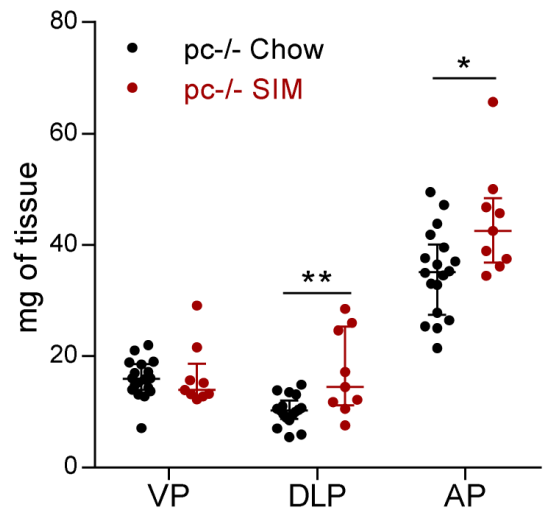

C

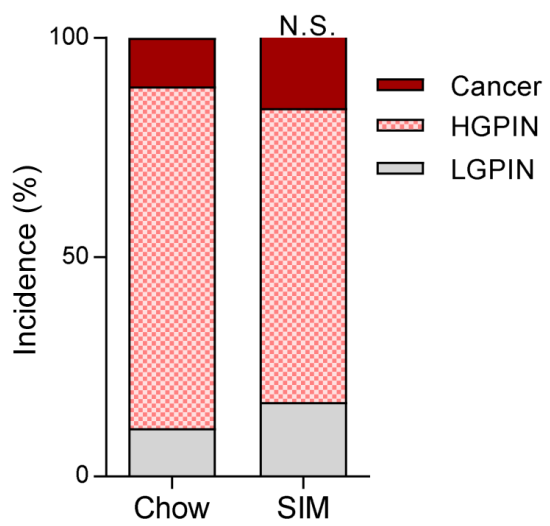

e

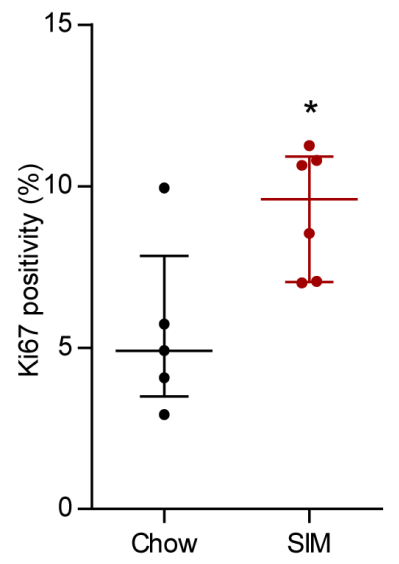

Figure 2: Simvastatin administration increases feature of aggressiveness in prostate cancer initiation. a. Schematic representation of the experimental design. 8 week-old Pten-deficient (Pten $\left.{ }^{p c-/} ; p c-/-\right)$ mice were fed with simvastatin-loaded (SIM) diet or chow for four weeks, and tissues were harvested and analysed. b. Prostate lobe weights of Pten-deficient mice fed chow ( $p c-/-$ Chow, $n$ $=18$ ) and SIM diet ( $p c-/$ SIM, $n=9)$. VP, DLP, AP refer to ventral, dorsolateral and anterior prostates respectively. c. Histopathological characterization of the prostate. (LGPIN: Low-grade prostatic intraepithelial neoplasia; HGPIN: High-grade prostatic intraepithelial neoplasia; Cancer: prostate adenocarcinoma) (Chow, $n=9$; SIM, $n=6$ ). d. Representative histological images of the prostate. Left, H\&E (Haematoxylin-Eosin) and right, Ki67 staining, showing prostate intraepithelial neoplasia (PIN) in Pten-deficient mice fed with SIM or chow. e. Quantification of Ki67 positive nuclei (\%), indicating proliferating cells, in $p c-/-$ Chow $(n=5)$ and $p c-/-$ SIM $(n=6)$. Statistical analysis: Mann-Whitney statistic test (b,e) and Chi Square test with 2 degree freedom (c). Error bars represent median with interquartile range. N.S.: Non-significant. ${ }^{*} p<0.05,{ }^{*} p<0.01$. 
dependent) and 22RV1 (AR-independent) cell lines. None of these parameters (AR protein levels or activity by means of the mRNA abundance of its target KLK3; AKT or ERK phosphorylation) was consistently altered neither in vitro nor in vivo, thus precluding their involvement as a major component of the mechanism of action of statins (Supplementary Figure 3; unprocessed scans in Supplementary Figure 5). Of note, we also monitored

a

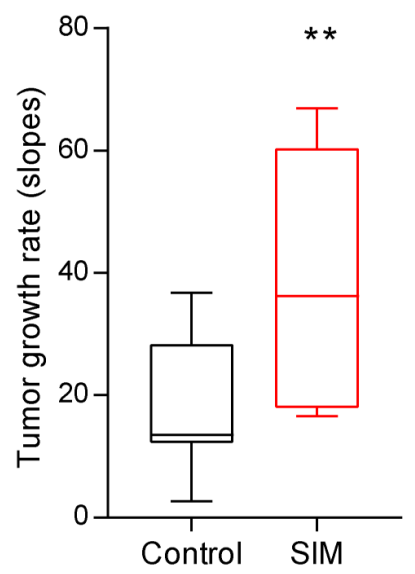

C
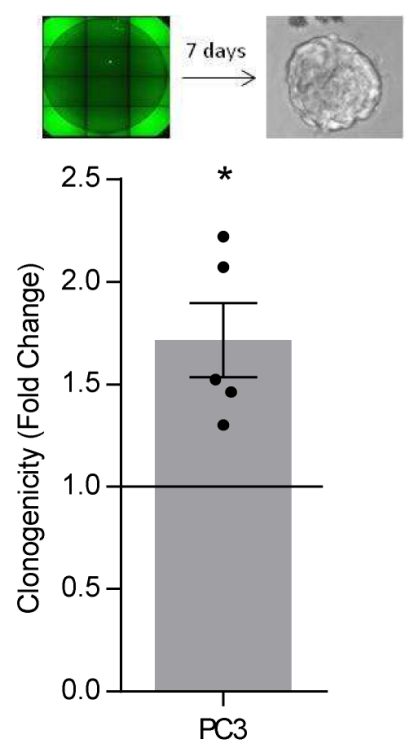

the expression of cholesterol transporters and metabolic enzymes that could be altered as a consequence of statin treatment $[48,49]$. We did not observe consistent changes neither in low density lipoprotein receptor (LDLR) nor in other enzymes and transporters (Apolipoprotein (APO) genes, ACAT1 (acetyl CoA cholesterol acyl transferase) and 2 and lipoprotein lipase (LPL)), precluding a major involvement of such alterations in the biological effect of

b

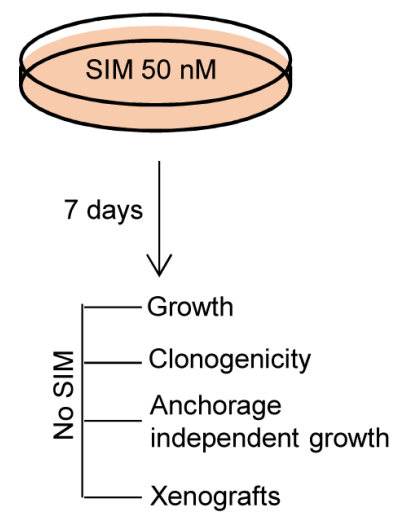

d

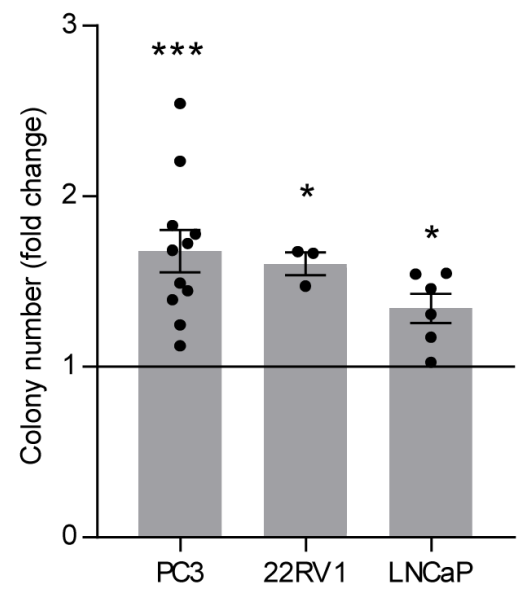

Figure 3: Low-dose simvastatin enhances features of prostate cancer aggressiveness in vitro and in vivo. a. Tumor growth rate from PC3 cell xenografts upon feeding nude mice with chow or simvastatin-loaded (SIM) diet. 5 mice for condition were used, 4 tumors per mouse. 100.000 PC3 cells were injected. Mice were fed with simvastatin loaded chow starting $72 \mathrm{~h}$ before injections. Box plot representation. b. Schematic representation of simvastatin treatment in vitro in PC3 cells. Cells were pre-treated for 7 days with $50 \mathrm{nM}$ simvastatin, and biological effects were evaluated. c. Effect of simvastatin pre-treatment on clonal self-renewal capacity $(n=5)$ in PC3 cells. d, Effect of $50 \mathrm{nM}$ simvastatin pre-treatment on anchorage-independent growth in PC3, 22RV1 and LNCaP cell lines. Statistical analysis: Mann Whitney test (a), one sample t test (c, d. Error bars represent standard error of the mean. ${ }^{*} p<0.05,{ }^{* *} p<0.01, * * * p<0.001$. 
these compounds (Supplementary Figure 4).

Observational studies have evaluated the association of statins to $\mathrm{PCa}$ risk and aggressiveness (Supplementary Table 3) [50, 51]. Our data suggests that there could be a subset of PCa patients where statins could exert undesirable effects. We analyzed data from a prospective study conducted in Vall d'Hebron Research Institute [15]. To carry out this analysis, 2408 men were selected, after excluding those men who were undergoing 5 - $\alpha$-reductase inhibitors treatment and those men who had been using statins for less than three years. In this cohort, the impact of statins was previously evaluated as part of a multivariate analysis with other factors such as age, PSA or serum cholesterol levels; or in combination with plasma cholesterol or aspirin treatment $[15,40]$. $37.2 \%$ of patients passed the statin treatment criteria beyond 3 years. In the multivariate study, statins were not associated to PCa risk. PCa was detected in 848 men $(35.2 \%)$, and 297 of them (35\%) were classified as high grade (HGPCa, Gleason score $>7$; as compared to Low Grade PCa (LGPCa; Gleason score $\leq 7)$ ). In line with previous reports, treatment with this family of compounds reduced the risk of suffering from $\mathrm{PCa}$ (overall risk (OR) $=0.717 ; p=0.006$ ). However, $41.8 \%$ of patients treated with statins were diagnosed with HGPCa, whereas aggressive disease was less prevalent among patients not taking the cholesterol-lowering drug $(32.5 \%$ of statin non-treated patients presented HGPCa, $p=0.012$, OR 1.495 (1095-2.039)) (Supplementary Table 4). To which extent the effect of statins is a predominant selective effect reducing the incidence of LGPCa, or whether it has an activity promoting the appearance of HGPCa remains to be studied, since both scenarios could lead to the results obtained in our analysis. In addition, our observational study does not account for statin dose, which, according to our experimental data, could be an important factor. Of note, these results are in line with the increased risk of high grade cancer reported in patients subject to statins that show normalized serum cholesterol levels [15], or patients with combined treatment of statins and aspirin [40]. Importantly, these results were corroborated in a multivariate analysis with other chronic pharmacological treatments (Supplementary Table 5). It should be noted that the controversy in observational studies with statins remains high [52], and additional analysis in wellannotated cohorts is granted.

\section{DISCUSSION}

Systemic metabolic alterations impact on the function and cross-talk of cells in our body. Indeed, the incidence and aggressiveness of cancer is in part associated to non-cell autonomous factors, such as nutrition, obesity or chronic therapeutic regimes [3, 53]. Statins are administered to millions of people worldwide. In turn, their consequences on tumor biology have become a research field of great interest. We have studied the consequences of statin treatment in $\mathrm{PCa}$ biology, and demonstrated through the use of a wide array of pre-clinical and experimental approaches that these compounds promote features of disease aggressiveness. It should be noted that our experimental systems might reflect the existence of a sub-population of PCa patients for whom statins have undesirable effects, in line with other studies [54, 55]. Interestingly, a large study of 47294 individuals focused on the study of coronary heart disease observed that patients treated with low-dose simvastatin (5-10 mg/day) and achieving low total serum cholesterol, presented increased risk of developing cancer $(\mathrm{OR}=$ 3.16 for serum cholesterol $<160$; OR $=1.85$ for serum cholesterol $=160-179$ ) [56]. The analysis of the available observational studies supports the existence of a context where statins could increase the aggressiveness of the disease in PCa patients. Overall, current epidemiological studies [15, 40, 50, 51, 54-68] would benefit of re-analysis taking into account this new information.

Experimental cancer systems often serve for the validation and causal demonstration of observations originated in patient studies. However, these approaches can also be employed to predict the consequences of societal or lifestyle changes. Our experimental systems provide very provocative results that still lack full clinical validation to demonstrate the potential existence of a subset of PCa patients in which statins exert an undesired activity. Our results warrant further analysis of the cell autonomous and systemic impact of statin treatment in $\mathrm{PCa}$ and other cancers in order to understand the biological context associated to a protective or detrimental activity of these compounds.

\section{MATERIALS AND METHODS}

\section{Cellular and molecular assays}

Human prostate carcinoma cell lines (PC3, LNCaP and 22RV1) were purchased from LeibnizInstitut - Deutsche Sammlung von Mikroorganismen und Zellkulturen GmbH (DSMZ, Germany), who provided authentication certificate. In addition, we validated their identity by microsatellite analysis. Cell lines were routinely monitored for mycoplasma contamination. Simvastatin and mevalonate (Sigma-Aldrich) for in vitro purposes were activated by heating $\left(50^{\circ} \mathrm{C}\right)$ with $\mathrm{NaOH}$ $(0.1 \mathrm{~N})$ for two hours. Fluvastatin (Sigma-Aldrich) was used following manufacturers' indications.

For clonogenicity assay, PC3 cells expressing GFP were plated in poly-HEMA pretreated 384 plates at 1 cell per well in DMEM/F12 (Gibco) plus EGF (100 mg/ml), bFGF $(10 \mathrm{mg} / \mathrm{ml})$, B27 (Thermo Fisher), 8\% BSA (SigmaAldrich). Wells with 0,1 , or $>1$ cells were annotated. 7 
days after plating, sphere formation from wells with single cells was quantified. Crystal violet-based cell number quantification, soft-agar anchorage independent growth and western blotting were performed as previously described [10]. Antibodies used for western blotting: androgen receptor (clone D6F11, Cell Signaling \#5153), phosphorylated ERK (T202/204; extracellular signal regulated kinase, clone 20G11, Cell Signaling \#4376), phosphorylated AKT (S473; clone 736E11, Cell Signaling \#3787), ERK (clone 3A7, Cell Signalling \#9107), AKT (Cell Signalling \#9272), $\beta$-Actin (clone AC-74; Sigma \#A5316), LDLR (EP1553Y; Abcam \#ab52818) and HSP90 (Heat Shock Protein 90, Cell Signaling \#4874).

RNA was extracted using NucleoSpin ${ }^{\circledR}$ RNA isolation kit from Macherey-Nagel (ref: 740955.240C). For RNA harvesting from mouse tissue, we introduced a prior step consisting on the incubation of the tissue in RNAlater ICE (Thermo Fisher) overnight at $-20^{\circ} \mathrm{C}$ and phenolic extraction with TRIreagent (TR118, MRC). In all cases, $1 \mu \mathrm{g}$ of total RNA was used for cDNA synthesis using qScript cDNA Supermix from Quanta (ref. 95048). Quantitative Real Time PCR (qRTPCR) was performed as previously described [10]. Universal Probe Library (Roche) primers and probes employed in human samples: $H M G C R$, primers: Fw: gttcggtggcctctagtgag, Rv: gcattcgaaaaagtcttgacaac; Probe: 65. KLK3, primers: Fw: gtgettgtggectctcgt Rv: agcaagatcacgettttgttc; Probe: 44. LDLR, primers: Fw: gatagtgacaatgtctcaccaagc, Rv: cctcacgctactgggcttc; Probe: 6. APOD, primers: Fw: gagaggccagtcaccaagac, Rv: gagaagggacctggagcttt; Probe: 8. $A P O A 2$, primers: Fw: gagaaggtcaagagcccaga, Rv: cettcttgatcaggggtgtc; Probe: 68. APOC1, primers: Fw: gecttggataagctgaagga, Rv: gaaatgtctctgaaaaccactcc; Probe: 47. $L P L$, primers: Fw: caggcctttgagatttctctgt, Rv: gaaggagtaggtcttatttgtggaa; Probe: 13. Universal Probe Library (Roche) primers and probes employed for mice: $L d l r$, primers: Fw: gatggctatacctaccctcaa, Rv: tgctcatgccacatcgtc; Probe: 64. ApoD, primers Fw: aatttccatcttgggaaatgc, Rv: ggatcttctcaatttcgtaccatc; Probe: 63. ApoC1, primers $F w$ : tgggaacactttggaagaca, $R v$ : actttgccaaatgcetctga; Probe: 46. ApoA2, primers Fw: tgctggtcaccatctgtagc, Rv: catatccggtccgtctgc; Probe: 12. ApoE, primers Fw: ttggtcacattgctgacagg, Rv: agcgcaggtaatcccagaa; Probe: 32. Lpl, Fw: tttgtgaaatgccatgacaag, Rv: cagatgctttcttctcttgtttgt; Probe: 47. Acat1, Fw: ggctgaactcagtaaccacaca, Rv: ttggettctagccgattcc; Probe: 71. Acat2, Fw: attccagccataaagcaagc, Rv: tttagctattgccgcagaca; Probe: 88. $\beta$-ACTIN and GAPDH housekeeping assays from Applied Biosystems $(\beta$-ACTIN, Hs99999903_m1; GAPDH, Hs02758991_g1; Mm99999915_g1); showed similar results (all qRTPCR data presented was normalized using $G A P D H)$.

Lentiviral shRNA sequences targeting HMGCR (TRCN0000262852 and TRCN0000262856, Sigma Mission Library) were cloned into TET-pLKO puro vector (gift from Dr. Dmitri Wiederschain [11], Addgene plasmid \#21915). HMGCR over-expressing lentiviral plasmid (pLX304) was obtained from https://plasmid.med.harvard. edu (HsCD00412328).

\section{Animals}

All mouse experiments were carried out following the ethical guidelines established by the Biosafety and Welfare Committee at CIC bioGUNE. The procedures employed were carried out following the recommendations from AAALAC. Xenograft experiments were performed as previously described [12], injecting $10^{5}$ cells per condition in two flanks per mouse (male Hsd:Athymic Nude-Foxn1 nu/nu). For metastasis experiment, $6 \times 10^{5}$ cells in $200 \mu \mathrm{l}$ were injected by tail vein [12]. When possible, mice were injected randomly and xenografts measured blindly to reduce bias due to caging. Western diet (SSNIFF, D12079 mod.) with high carbohydrates and fat (50\% carbohydrates, $21 \%$ fat) was compared with the $4 \%$ fat of the control diet. Simvastatin was provided in the diets (both standard diet and western diet) at 12 $\mathrm{mg} / \mathrm{kg}$ chow. The supplied concentration of simvastatin in mice was equivalent to $12 \mathrm{mg}$ /day in humans, which corresponded to low doses for anticholesterolemic treatment (the standard dose being $40 \mathrm{mg}$ /day).

The Pten $^{\text {loxP }}$ conditional knockout alleles have been described elsewhere [13]. Prostate epithelium specific deletion was effected by the $\mathrm{Pb}-\mathrm{Cre} 4$. Mice were fasted for $6 \mathrm{~h}$ prior to tissue harvest in order to prevent metabolic alterations due to immediate food intake.

\section{Histopathological analysis}

Samples of prostate gland or lungs were fixed overnight in $10 \%$ neutral buffered formalin, embedded in paraffin and sectioned $5 \mu \mathrm{m}$ thick and dried. Slides were dewaxed and re-hydrated through a series of graded ethanol until water and were stained with hematoxilineosin (H-E). Histopathological lesions of the prostate were classified according to current histological criteria [14].

Detection of PC3 in lungs metastatic foci of immunocompromised mice in the metastasis assay was assessed by immunohistochemical staining of Vimentin (NCL-L-VIM-572, Leica biosystems) using the streptavidin-biotin-peroxidase complex.

Proliferation was evaluated in paraffin embedded prostate samples by using Ki67 antibody (MA5-14520, Thermo Scientific). Five fields, at least 400 cells each field from the AP (anterior prostate) lobe were counted.

Immunohistochemical stainings of AR, pERK, pAKT and LDLR (references as in western blot analysis) were performed on deparaffinized prostate sections using the streptavidin-biotin-complex peroxidase method. Antigen retrieval was carried out by heating sections in 
$10 \mathrm{mM}$ sodium citrate, $\mathrm{pH}$ 6.0. Immunodetection was performed with the Polink-2 HRP Plus Rabbit Detection System (D39-110, GBI Labs, Bothell, WA, USA) and slides were developed with the peroxidase substrate kit (SK-4105, Vector Laboratories, Burlingame, CA, USA). Staining score 0 to 3 was given by two independent investigators based on the $\%$ of stained cells and the intensity of the staining.

\section{Patients}

We analysed data from a prospective study conducted in Vall d'Hebron Research Institute [15]. To carry out this analysis, 2408 men were selected, after excluding those men who were undergoing 5 - $\alpha$-reductase inhibitors treatment and those men who had been using statins for less than three years. Prostate cancer (PCa) was detected in 848 men (35.2\%), and 240 (28.3\%) were high grade prostate cancer (HGPCa) (Gleason score $>7$ ). The overall demographics and clinical characteristics of the men enrolled, as well as the methodological aspects have been previously reported [15].

\section{Statistics}

For patient analysis, quantitative variables were expressed as medians + semi-interquartile range. Qualitative variables were expressed as rates. Univariate analysis included the Chi-square test to analyse the association between qualitative variables and the Cochran test to evaluate their strength. Multivariate analysis using the binary logistic regression was carried out to examine the independent predictors of PCa risk and tumor aggressiveness. Odds ratios (OR) and 95\% coefficient interval (CI) were calculated.

For in vivo studies, in the absence of normal distribution, a non-parametric Mann Whitney U test was applied for two-group comparisons. For frequency analysis, Chi-square test was used when there were more than 2 variables and Fisher $F$ test was used for 2 variables. For in vitro experiments, normal distribution was assumed and one sample t-test was applied for one component comparisons with control. Error bars represent mean \pm SEM (standard error of the mean) in vitro, and median with interquartile range in vivo, unless otherwise specified. We considered $p<0.05$ to be statistically significant.

\section{Author contributions}

AC-M performed the majority of in vitro and in vivo experiments, unless specified otherwise. LC performed in vitro analysis and immunohistochemistry. AZ performed the in vivo obesity and simvastatin treatment in $\mathrm{Pten}^{p^{c+/}}$ mice. VT, SF-R, KZ, LA, LV-J, NM-M contributed to in vitro experiments and analysis. JMF provided the diagnosis of mouse prostate tissue. ARC provided Support with statistical analysis. PZ, AA-A, FG, DC, SMVL, JMF-P, AMA and AG-M provided technical support and critical discussions. MO and JM performed the human patient analysis in the VHIR cohort. AC directed the project, supervised data analysis and wrote the manuscript.

\section{ACKNOWLEDGMENTS AND GRANT SUPPORT}

Apologies to those whose related publications were not cited due to space limitations. AC-M is supported by the MINECO postdoctoral program and the CIG program from the European commission (660191). NM-M was supported by the Spanish Association Against Cancer (AECC), AECC JP Vizcaya. VT is supported by Fundación Vasca de Innovación e Investigación Sanitarias, BIOEF (BIO15/CA/052), the department of health of the Basque Government (2016111109) and the 2016 grant of the AECC (Junta provincial de Bizkaia). LA, AA-A and LV-J were supported by the Basque Government of education. The work of A.C. is supported by the Ramón y Cajal award, the Basque Department of Industry, Tourism and Trade (Etortek) and the department of education (IKERTALDE IT1106-16), ISCIII (PI10/01484, PI13/00031), FERO VIII Fellowship, the BBVA foundation, the MINECO (SAF2016-79381-R), Severo Ochoa Excellence Accreditation SEV-2016-0644) and the European Research Council (Starting Grant 336343; Proof of Concept 754627). The participation of AC, VT, NM-M, SF and AZ as part of CIBERONC was co-funded with FEDER funds.

\section{CONFLICTS OF INTEREST}

The authors declare no conflicts of interest.

\section{REFERENCES}

1. Martincorena I, Campbell PJ. Somatic mutation in cancer and normal cells. Science. 2015; 349: 1483-9. doi: 10.1126/ science.aab4082.

2. Hanahan D, Weinberg RA. Hallmarks of cancer: the next generation. Cell. 2011; 144: 646-74. doi: 10.1016/j. cell.2011.02.013.

3. Calle EE, Rodriguez C, Walker-Thurmond K, Thun MJ. Overweight, obesity, and mortality from cancer in a prospectively studied cohort of U.S. adults. N Engl J Med. 2003; 348: 1625-38. doi: 10.1056/NEJMoa021423.

4. Bail J, Meneses K, Demark-Wahnefried W. Nutritional Status and Diet in Cancer Prevention. Semin Oncol Nurs. 2016; 32: 206-14. doi: 10.1016/j.soncn.2016.05.004.

5. Marosi C, Koller M. Challenge of cancer in the elderly. ESMO Open. 2016; 1: e000020. doi: 10.1136/ 
esmoopen-2015-000020.

6. Williams GR, Mackenzie A, Magnuson A, Olin R, Chapman A, Mohile S, Allore H, Somerfield MR, Targia V, Extermann M, Cohen HJ, Hurria A, Holmes H. Comorbidity in older adults with cancer. J Geriatr Oncol. 2016; 7: 249-57. doi: 10.1016/j.jgo.2015.12.002.

7. Hsing AW, Chokkalingam AP. Prostate cancer epidemiology. Front Biosci. 2006; 11: 1388-413.

8. Quagliariello V, Rossetti S, Cavaliere C, Di Palo R, Lamantia E, Castaldo L, Nocerino F, Ametrano G, Cappuccio F, Malzone G, Montanari M, Vanacore D, Romano FJ, et al. Metabolic syndrome, endocrine disruptors and prostate cancer associations: biochemical and pathophysiological evidences. Oncotarget. 2017; 8: 3060616. doi: 10.18632/oncotarget.16725.

9. Collins R, Reith C, Emberson J, Armitage J, Baigent C, Blackwell L, Blumenthal R, Danesh J, Smith GD, DeMets D, Evans S, Law M, MacMahon S, et al. Interpretation of the evidence for the efficacy and safety of statin therapy. Lancet. 2016; 388: 2532-61. doi: 10.1016/S01406736(16)31357-5.

10. Torrano V, Valcarcel-Jimenez L, Cortazar AR, Liu X, Urosevic J, Castillo-Martin M, Fernandez-Ruiz S, Morciano G, Caro-Maldonado A, Guiu M, Zuniga-Garcia P, Graupera M, Bellmunt A, et al. The metabolic co-regulator PGC1alpha suppresses prostate cancer metastasis. Nat Cell Biol. 2016; 18: 645-56. doi: 10.1038/ncb3357.

11. Wiederschain D, Wee S, Chen L, Loo A, Yang G, Huang A, Chen Y, Caponigro G, Yao YM, Lengauer C, Sellers WR, Benson JD. Single-vector inducible lentiviral RNAi system for oncology target validation. Cell Cycle. 2009; 8: 498-504.

12. Martin-Martin N, Piva M, Urosevic J, Aldaz P, Sutherland JD, Fernandez-Ruiz S, Arreal L, Torrano V, Cortazar AR, Planet E, Guiu M, Radosevic-Robin N, Garcia S, et al. Stratification and therapeutic potential of PML in metastatic breast cancer. Nat Commun. 2016; 7: 12595. doi: 10.1038/ ncomms 12595 .

13. Chen Z, Trotman LC, Shaffer D, Lin HK, Dotan ZA, Niki M, Koutcher JA, Scher HI, Ludwig T, Gerald W, CordonCardo C, Pandolfi PP. Crucial role of p53-dependent cellular senescence in suppression of Pten-deficient tumorigenesis. Nature. 2005; 436: 725-30. doi: nature03918.

14. Ittmann M, Huang J, Radaelli E, Martin P, Signoretti S, Sullivan R, Simons BW, Ward JM, Robinson BD, Chu GC, Loda M, Thomas G, Borowsky A, et al. Animal models of human prostate cancer: the consensus report of the New York meeting of the Mouse Models of Human Cancers Consortium Prostate Pathology Committee. Cancer Res. 2013; 73: 2718-36. doi: 10.1158/0008-5472.CAN-12-4213.

15. Morote J, Celma A, Planas J, Placer J, de Torres I, Olivan M, Carles J, Reventos J, Doll A. Role of serum cholesterol and statin use in the risk of prostate cancer detection and tumor aggressiveness. Int J Mol Sci. 2014; 15: 13615-23. doi: 10.3390/ijms150813615.
16. Feingold KR, Grunfeld C. Obesity and Dyslipidemia. In: De Groot LJ, Chrousos G, Dungan K, Feingold KR, Grossman A, Hershman JM, Koch C, Korbonits M, McLachlan R, New M, Purnell J, Rebar R, Singer F, Vinik A, Editors. Endotext. South Dartmouth: Mass. Endotext.org; 2000.

17. Nardella C, Carracedo A, Salmena L, Pandolfi PP. Faithfull modeling of PTEN loss driven diseases in the mouse. Curr Top Microbiol Immunol. 2011; 347: 135-68. doi: 10.1007/82_2010_62.

18. Boudreau DM, Yu O, Johnson J. Statin use and cancer risk: a comprehensive review. Expert Opin Drug Saf. 2010; 9: 603-21. doi: 10.1517/14740331003662620.

19. Miller RA, Harrison DE, Astle CM, Baur JA, Boyd AR, de Cabo R, Fernandez E, Flurkey K, Javors MA, Nelson JF, Orihuela CJ, Pletcher S, Sharp ZD, et al. Rapamycin, but not resveratrol or simvastatin, extends life span of genetically heterogeneous mice. J Gerontol A Biol Sci Med Sci. 2011; 66: 191-201. doi: 10.1093/gerona/glq178.

20. Blumenthal RS. Statins: effective antiatherosclerotic therapy. Am Heart J. 2000; 139: 577-83.

21. Hammond CL, Wheeler SG, Ballatori N, Hinkle PM. Ostalpha-/- mice are not protected from western dietinduced weight gain. Physiol Rep. 2015; 3. doi: 10.14814/ phy2.12263.

22. Merseburger AS, Alcaraz A, von Klot CA. Androgen deprivation therapy as backbone therapy in the management of prostate cancer. Onco Targets Ther. 2016; 9: 7263-74. doi: 10.2147/OTT.S117176.

23. Carver BS, Chapinski C, Wongvipat J, Hieronymus H, Chen Y, Chandarlapaty S, Arora VK, Le C, Koutcher J, Scher H, Scardino PT, Rosen N, Sawyers CL. Reciprocal feedback regulation of $\mathrm{PI} 3 \mathrm{~K}$ and androgen receptor signaling in PTEN-deficient prostate cancer. Cancer Cell. 2011; 19: 575-86. doi: S1535-6108(11)00155-3.

24. Aberg M, Johnell M, Wickstrom M, Widunder A, Siegbahn A. Simvastatin reduces the production of prothrombotic prostasomes in human prostate cancer cells. Thromb Haemost. 2008; 100: 655-62.

25. Al-Husein B, Goc A, Somanath PR. Suppression of interactions between prostate tumor cell-surface integrin and endothelial ICAM-1 by simvastatin inhibits micrometastasis. J Cell Physiol. 2013; 228: 2139-48. doi: 10.1002/jcp. 24381.

26. Babcook MA, Shukla S, Fu P, Vazquez EJ, Puchowicz MA, Molter JP, Oak CZ, MacLennan GT, Flask CA, Lindner DJ, Parker Y, Daneshgari F, Gupta S. Synergistic simvastatin and metformin combination chemotherapy for osseous metastatic castration-resistant prostate cancer. Mol Cancer Ther. 2014; 13: 2288-302. doi: 10.1158/1535-7163.MCT14-0451.

27. Brown M, Hart C, Tawadros T, Ramani V, Sangar V, Lau M, Clarke N. The differential effects of statins on the metastatic behaviour of prostate cancer. Br J Cancer. 2012; 106: 1689-96. doi: 10.1038/bjc.2012.138. 
28. Chang HL, Chen CY, Hsu YF, Kuo WS, Ou G, Chiu PT, Huang YH, Hsu MJ. Simvastatin induced HCT116 colorectal cancer cell apoptosis through p38MAPK-p53survivin signaling cascade. Biochim Biophys Acta. 2013; 1830: 4053-64. doi: 10.1016/j.bbagen.2013.04.011.

29. Costa RA, Fernandes MP, de Souza-Pinto NC, Vercesi AE. Protective effects of 1-carnitine and piracetam against mitochondrial permeability transition and PC3 cell necrosis induced by simvastatin. Eur J Pharmacol. 2013; 701: 82-6. doi: 10.1016/j.ejphar.2013.01.001.

30. Crosbie J, Magnussen M, Dornbier R, Iannone A, Steele TA. Statins inhibit proliferation and cytotoxicity of a human leukemic natural killer cell line. Biomark Res. 2013; 1: 33. doi: 10.1186/2050-7771-1-33.

31. Furuya Y, Sekine Y, Kato H, Miyazawa Y, Koike H, Suzuki K. Low-density lipoprotein receptors play an important role in the inhibition of prostate cancer cell proliferation by statins. Prostate Int. 2016; 4: 56-60. doi: 10.1016/j. prnil.2016.02.003.

32. Goc A, Kochuparambil ST, Al-Husein B, Al-Azayzih A, Mohammad S, Somanath PR. Simultaneous modulation of the intrinsic and extrinsic pathways by simvastatin in mediating prostate cancer cell apoptosis. BMC Cancer. 2012; 12: 409. doi: 10.1186/1471-2407-12-409.

33. Hoque $\mathrm{A}$, Chen $\mathrm{H}, \mathrm{Xu} \mathrm{XC}$. Statin induces apoptosis and cell growth arrest in prostate cancer cells. Cancer Epidemiol Biomarkers Prev. 2008; 17: 88-94. doi: 10.1158/1055-9965. EPI-07-0531.

34. Ingersoll MA, Miller DR, Martinez O, Wakefield CB, Hsieh KC, Simha MV, Kao CL, Chen HT, Batra SK, Lin MF. Statin derivatives as therapeutic agents for castrationresistant prostate cancer. Cancer Lett. 2016; 383: 94-105. doi: 10.1016/j.canlet.2016.09.008.

35. Kim JH, Cox ME, Wasan KM. Effect of simvastatin on castration-resistant prostate cancer cells. Lipids Health Dis. 2014; 13: 56. doi: 10.1186/1476-511X-13-56.

36. Kochuparambil ST, Al-Husein B, Goc A, Soliman S, Somanath PR. Anticancer efficacy of simvastatin on prostate cancer cells and tumor xenografts is associated with inhibition of Akt and reduced prostate-specific antigen expression. J Pharmacol Exp Ther. 2011; 336: 496-505. doi: 10.1124/jpet.110.174870.

37. Kureishi Y, Luo Z, Shiojima I, Bialik A, Fulton D, Lefer DJ, Sessa WC, Walsh K. The HMG-CoA reductase inhibitor simvastatin activates the protein kinase Akt and promotes angiogenesis in normocholesterolemic animals. Nat Med. 2000; 6: 1004-10. doi: 10.1038/79510.

38. Liang Z, Li W, Liu J, Li J, He F, Jiang Y, Yang L, Li P, Wang B, Wang Y, Ren Y, Yang J, Luo Z, et al. Simvastatin suppresses the DNA replication licensing factor MCM7 and inhibits the growth of tamoxifen-resistant breast cancer cells. Sci Rep. 2017; 7: 41776. doi: 10.1038/srep41776.

39. Menter DG, Ramsauer VP, Harirforoosh S, Chakraborty K, Yang P, Hsi L, Newman RA, Krishnan K. Differential effects of pravastatin and simvastatin on the growth of tumor cells from different organ sites. PLoS One. 2011; 6: e28813. doi: 10.1371/journal.pone.0028813.

40. Olivan M, Rigau M, Colas E, Garcia M, Montes M, Sequeiros T, Regis L, Celma A, Planas J, Placer J, Reventos J, de Torres I, Doll A, et al. Simultaneous treatment with statins and aspirin reduces the risk of prostate cancer detection and tumorigenic properties in prostate cancer cell lines. Biomed Res Int. 2015; 2015: 762178. doi: $10.1155 / 2015 / 762178$.

41. Oliveira KA, Zecchin KG, Alberici LC, Castilho RF, Vercesi AE. Simvastatin inducing PC3 prostate cancer cell necrosis mediated by calcineurin and mitochondrial dysfunction. J Bioenerg Biomembr. 2008; 40: 307-14. doi: 10.1007/s10863-008-9155-9.

42. Park YH, Seo SY, Lee E, Ku JH, Kim HH, Kwak C. Simvastatin induces apoptosis in castrate resistant prostate cancer cells by deregulating nuclear factor-kappaB pathway. J Urol. 2013; 189: 1547-52. doi: 10.1016/j. juro.2012.10.030.

43. Rogers M, Kalra S, Moukharskaya J, Chakraborty K, Niyazi M, Krishnan K, Lightner J, Brannon M, Stone WL, Palau VE. Synergistic growth inhibition of PC3 prostate cancer cells with low-dose combinations of simvastatin and alendronate. Anticancer Res. 2015; 35: 1851-9. doi:

44. Stine JE, Guo H, Sheng X, Han X, Schointuch MN, Gilliam TP, Gehrig PA, Zhou C, Bae-Jump VL. The HMG-CoA reductase inhibitor, simvastatin, exhibits anti-metastatic and anti-tumorigenic effects in ovarian cancer. Oncotarget. 2016; 7: 946-60. doi: 10.18632/oncotarget.5834.

45. Wang G, Cao R, Wang Y, Qian G, Dan HC, Jiang W, Ju L, Wu M, Xiao Y, Wang X. Simvastatin induces cell cycle arrest and inhibits proliferation of bladder cancer cells via PPARgamma signalling pathway. Sci Rep. 2016; 6: 35783. doi: $10.1038 /$ srep35783.

46. Backman JT, Kyrklund C, Kivisto KT, Wang JS, Neuvonen PJ. Plasma concentrations of active simvastatin acid are increased by gemfibrozil. Clin Pharmacol Ther. 2000; 68: 122-9. doi: 10.1067/mcp.2000.108507.

47. Lambert AW, Pattabiraman DR, Weinberg RA. Emerging Biological Principles of Metastasis. Cell. 2017; 168: 67091. doi: 10.1016/j.cell.2016.11.037.

48. Guillaumond F, Bidaut G, Ouaissi M, Servais S, Gouirand $\mathrm{V}$, Olivares $\mathrm{O}$, Lac S, Borge L, Roques J, Gayet O, Pinault M, Guimaraes C, Nigri J, et al. Cholesterol uptake disruption, in association with chemotherapy, is a promising combined metabolic therapy for pancreatic adenocarcinoma. Proc Natl Acad Sci U S A. 2015; 112: 2473-8. doi: 10.1073/ pnas.1421601112.

49. Vasseur S, Guillaumond F. LDL Receptor: An open route to feed pancreatic tumor cells. Mol Cell Oncol. 2016; 3: e1033586. doi: 10.1080/23723556.2015.1033586.

50. Bonovas S, Filioussi K, Sitaras NM. Statin use and the risk of prostate cancer: A metaanalysis of 6 randomized clinical 
trials and 13 observational studies. Int J Cancer. 2008; 123 : 899-904. doi: 10.1002/ijc.23550.

51. Tan P, Zhang C, Wei SY, Tang Z, Gao L, Yang L, Wei Q. Effect of statins type on incident prostate cancer risk: a meta-analysis and systematic review. Asian J Androl. 2016. doi: 10.4103/1008-682X.190327.

52. Schnoeller TJ, Jentzmik F, Schrader AJ, Steinestel J. Influence of serum cholesterol level and statin treatment on prostate cancer aggressiveness. Oncotarget. 2017; 8: 4711020. doi: 10.18632/oncotarget.16943.

53. Evans JM, Donnelly LA, Emslie-Smith AM, Alessi DR, Morris AD. Metformin and reduced risk of cancer in diabetic patients. BMJ. 2005; 330: 1304-5. doi: 10.1136/ bmj.38415.708634.F7.

54. Chang CC, Ho SC, Chiu HF, Yang CY. Statins increase the risk of prostate cancer: a population-based casecontrol study. Prostate. 2011; 71: 1818-24. doi: 10.1002/ pros. 21401 .

55. Wettstein MS, Saba K, Umbehr MH, Murtola TJ, Fankhauser CD, Adank JP, Hofmann M, Sulser T, Hermanns T, Moch H, Wild P, Poyet C. Prognostic Role of Preoperative Serum Lipid Levels in Patients Undergoing Radical Prostatectomy for Clinically Localized Prostate Cancer. Prostate. 2017. doi: 10.1002/pros.23296.

56. Matsuzaki M, Kita T, Mabuchi H, Matsuzawa Y, Nakaya N, Oikawa S, Saito Y, Sasaki J, Shimamoto K, Itakura H, Trial JLSGJLI. Large scale cohort study of the relationship between serum cholesterol concentration and coronary events with low-dose simvastatin therapy in Japanese patients with hypercholesterolemia. Circ J. 2002; 66: 108795.

57. Allott EH, Farnan L, Steck SE, Arab L, Su LJ, Mishel M, Fontham ET, Mohler JL, Bensen JT. Statin Use and Prostate Cancer Aggressiveness: Results from the PopulationBased North Carolina-Louisiana Prostate Cancer Project. Cancer Epidemiol Biomarkers Prev. 2016; 25: 670-7. doi: 10.1158/1055-9965.EPI-15-0631.

58. Allott EH, Howard LE, Cooperberg MR, Kane CJ, Aronson WJ, Terris MK, Amling CL, Freedland SJ. Postoperative statin use and risk of biochemical recurrence following radical prostatectomy: results from the Shared Equal Access Regional Cancer Hospital (SEARCH) database. BJU Int. 2014; 114: 661-6. doi: 10.1111/bju.12720.

59. Bansal D, Undela K, D'Cruz S, Schifano F. Statin use and risk of prostate cancer: a meta-analysis of observational studies. PLoS One. 2012; 7: e46691. doi: 10.1371/journal. pone.0046691.

60. Chen HY, Wang Q, Xu QH, Yan L, Gao XF, Lu YH, Wang L. Statin as a Combined Therapy for AdvancedStage Ovarian Cancer: A Propensity Score Matched Analysis. Biomed Res Int. 2016; 2016: 9125238. doi: 10.1155/2016/9125238.

61. Ford I, Murray H, McCowan C, Packard CJ. LongTerm Safety and Efficacy of Lowering Low-Density
Lipoprotein Cholesterol With Statin Therapy: 20-Year Follow-Up of West of Scotland Coronary Prevention Study. Circulation. 2016; 133: 1073-80. doi: 10.1161/ CIRCULATIONAHA.115.019014.

62. Friedman GD, Flick ED, Udaltsova N, Chan J, Quesenberry CP Jr, Habel LA. Screening statins for possible carcinogenic risk: up to 9 years of follow-up of 361,859 recipients. Pharmacoepidemiol Drug Saf. 2008; 17: 27-36. doi: $10.1002 /$ pds. 1507 .

63. Huang BZ, Chang JI, Li E, Xiang AH, Wu BU. Influence of Statins and Cholesterol on Mortality Among Patients With Pancreatic Cancer. J Natl Cancer Inst. 2017; 109. doi: 10.1093/jnci/djw275.

64. Jespersen CG, Norgaard M, Friis S, Skriver C, Borre M. Statin use and risk of prostate cancer: a Danish populationbased case-control study, 1997-2010. Cancer Epidemiol. 2014; 38: 42-7. doi: 10.1016/j.canep.2013.10.010.

65. Krane LS, Kaul SA, Stricker HJ, Peabody JO, Menon M, Agarwal PK. Men presenting for radical prostatectomy on preoperative statin therapy have reduced serum prostate specific antigen. J Urol. 2010; 183: 118-24. doi: 10.1016/j. juro.2009.08.151.

66. Mamtani R, Lewis JD, Scott FI, Ahmad T, Goldberg DS, Datta J, Yang YX, Boursi B. Disentangling the Association between Statins, Cholesterol, and Colorectal Cancer: A Nested Case-Control Study. PLoS Med. 2016; 13: e1002007. doi: 10.1371/journal.pmed.1002007.

67. Platz EA, Leitzmann MF, Visvanathan K, Rimm EB, Stampfer MJ, Willett WC, Giovannucci E. Statin drugs and risk of advanced prostate cancer. J Natl Cancer Inst. 2006; 98: 1819-25. doi: 10.1093/jnci/djj499.

68. Pottegard A, Clark P, Friis S, Hallas J, Lund L. Longterm Use of Statins and Risk of Renal Cell Carcinoma: A Population-based Case-Control Study. Eur Urol. 2016; 69: 877-82. doi: 10.1016/j.eururo.2015.10.020. 